\title{
DIAGNÓSTICO DA ADOÇÃO DA VITICULTURA DE PRECISÃO NO VALE DOS VINHEDOS - RIO GRANDE DO SUL
}

\author{
Gracieli Manfrin da Silva Erthal ${ }^{1}$, Alexandre Russini ${ }^{1}$, Elódio Sebem ${ }^{1}$, Eduardo Santos Erthal ${ }^{2}$, Cristiano Galafassi ${ }^{3}$ \\ 1 Programa de Pós-Graduação em Agricultura de Precisão, Universidade Federal de Santa Maria, 97105-900, Santa Maria, Brasil. \\ ${ }^{2}$ Curso de Engenharia Ambiental e Sanitária, Universidade de Cruz Alta, 98020-290, Cruz Alta, Brasil. \\ ${ }^{3}$ Campus Itaqui, Universidade Federal do Pampa, 97650-000, Itaqui, Brasil
}

*E-mail: gracimanfrin@gmail.com

Recebido em: 06/05/2018 Aceito em: 13/06/2018

\begin{abstract}
RESUMO
$\mathrm{Na}$ viticultura, o uso das técnicas de agricultura de precisão (AP), nomeado neste caso de viticultura de precisão (VP), é considerado relativamente recente. Nesse sentido, o presente trabalho buscou realizar o diagnóstico da adoção das ferramentas e técnicas de VP por viticultores da região de Denominação de Origem Vale dos Vinhedos, situada no estado do Rio Grande do Sul - Brasil. A pesquisa realizada foi de caráter exploratório e descritivo, fazendo-se uso de técnicas de análise qualitativas e quantitativas. Os dados foram coletados através da aplicação de 21 questionários aos representantes de vinícolas da região. Foram identificados apenas 5 $(23,81 \%)$ viticultores adotantes de VP, evidenciando a baixa taxa de adoção da tecnologia na região. Dentre as técnicas e ferramentas de VP adotadas na Denominação de Origem Vale dos Vinhedos estão o georreferenciamento das áreas, os mapas de qualidade e produtividade, a aplicação de fertilizantes a taxa variada, a análise georreferenciada do solo, a aplicação de defensivos a taxa variada, a colheita segmentada e o monitoramento georreferenciado de parâmetros de qualidade da uva. Como dificuldades de uso da tecnologia de VP, as principais apontadas foram o alto custo e a dificuldade de operacionalizar as tecnologias, a falta de recursos para implantar o sistema completo e linhas de financiamento, bem como a falta de prestadores de serviço e o custo elevado destes. A baixa taxa de adoção desta tecnologia reflete a incipiente difusão da mesma entre os viticultores da região.
\end{abstract}

Palavras-chave: Agricultura de Precisão. Vitis vinífera. Denominação de Origem. Adoção de tecnologias.

\section{Introdução}

A vitivinicultura é sem dúvida uma atividade de grande importância econômica no mundo, o que se evidencia pelo seu estabelecimento há tempo relatado na história mundial. Atualmente, centenas de regiões vinícolas encontram-se demarcadas e os vinhos possuem uma estreita ligação com o aspecto local como, por exemplo, o clima e o solo, e as técnicas culturais utilizadas, conferindo uma identidade regional aos vinhos, a qual é conhecida pelo termo francês Terroir [1].

No Brasil, dentre os principais estados produtores, destaca-se o Rio Grande do Sul, responsável por $64,4 \%$ da área cultivada no país [2]. Dentre as regiões produtoras de uvas do estado, destaca-se a microrregião de Caxias do Sul, responsável por $87,1 \%$ da uva colhida no solo gaúcho em 2015 [3].

$\mathrm{Na}$ cadeia vitivinícola, as Indicações Geográficas representam o caminho para mudanças no realinhamento de seus produtos, buscando o reconhecimento da tipicidade $\mathrm{e}$ consequentemente a agregação de valor ao produto final. Na busca desse reconhecimento, em 2012 foi concedido o Registro de Denominação de Origem ao Vale dos Vinhedos, limitando uma área de $72,45 \mathrm{~km}^{2}$, compreendida entre os municípios de Bento
Gonçalves $(61,07 \%)$, Garibaldi $(33,49 \%)$ e Monte Belo do Sul $(5,44 \%)[4]$.

De acordo com Miele et al. [5], a produção e a comercialização dos vinhos finos brasileiros sofrem grande concorrência de produtos importados, especialmente de países da América do Sul e Europa. Com o intuito de abrandar esse panorama, nota-se o empenho das instituições ligadas ao setor, assim como de algumas empresas líderes, à procura de uma melhor qualidade dos vinhos através da adoção de tecnologias vitícolas e enológicas modernas. Miele et al. [6] ressaltam a viticultura de precisão como uma importante ferramenta para melhorar a qualidade do vinho produzido no Brasil.

A utilização da agricultura de precisão no cultivo da videira é uma tecnologia considerada nova, sendo que Esser [7] relata que a vitivinicultura de precisão surgiu primeiramente nos países inovadores em desenvolvimento tecnológico, como a Austrália e os Estados Unidos. Estudos quanto à adoção da agricultura de precisão vêm sendo realizados em países como EUA, Canadá, Alemanha, Dinamarca, entre outros [8], sendo que no Brasil, foram realizados estudos referentes à adoção de AP nas culturas da soja, milho, trigo, algodão, feijão, cana de açúcar e algodão. 
A viticultura de precisão engloba um conjunto de técnicas que busca caracterizar a variabilidade espacial do crescimento vegetativo da videira, da produção da uva e sua maturação, identificando os fatores que afetam esse processo, com o objetivo de aplicar um manejo adequado em cada zona ou parcela considerada [9]. Matese et al. [10], relatam que no setor vinícola as novas tecnologias podem garantir uma produção de vinhos de maior qualidade, com baixos custos de operação e boas colheitas, com vistas ao máximo potencial enológico dos vinhedos.

A eficácia da viticultura de precisão, no entanto, é dependente de condições como: se a variação espacial da produtividade possui certa estabilidade ano após ano; se as causas da variabilidade forem identificadas e, se estas causas podem ser geridas de forma diferenciada na parcela [11]. Além disso, esta tecnologia somente será considerada útil à medida que possibilitar ao viticultor produzir uvas de alta qualidade uniformemente para produção de vinhos finos [12].

Conhecida a potencial importância da utilização da viticultura de precisão, resta identificar se esta tecnologia está sendo implantada e se seus resultados estão sendo satisfatórios perante a perspectiva dos viticultores. Além disso, é importante visualizar os fatores que influenciam na adoção ou não desta tecnologia.

Diante desse contexto, o presente trabalho buscou realizar o diagnóstico sobre a adoção das ferramentas de viticultura de precisão (VP) por viticultores da região da Denominação de Origem Vale dos Vinhedos.

\section{Parte Experimental ou Metodologia}

O presente estudo foi realizado na região geográfica delimitada Denominação de Origem Vale dos Vinhedos, localizada a nordeste do estado do Rio Grande do Sul, na região serrana, mais especificamente na Microrregião Caxias do Sul, entre as latitudes $29^{\circ} 08^{\prime} 22^{\prime}$ 'S e $29^{\circ} 14^{\prime} 25^{\prime}$ 'S e as longitudes $51^{\circ} 29$ '49"W e 5138'00"W.

A pesquisa realizada baseou-se na metodologia desenvolvida e aplicada por Anselmi [8], a qual caracteriza-se como um estudo de caráter exploratório e descritivo, através do uso de técnicas de análise qualitativas e quantitativas.

Partindo da área de abrangência da D.O. Vale dos Vinhedos, compreendida entre os municípios de Bento Gonçalves, Garibaldi e Monte Belo do Sul, foi realizada uma pesquisa exploratória junto aos órgãos envolvidos no setor vitícola da região, tais como Embrapa Uva e Vinho, APROVALE (Associação dos produtores de vinhos finos do Vale dos Vinhedos), e IBRAVIN (Instituto Brasileiro do Vinho), no intuito de definir uma relação de vinícolas como alvo da pesquisa.

Através das informações fornecidas por estes órgãos, chegou-se a uma relação de 274 vinícolas presentes nos municípios constituintes da D.O. Vale dos Vinhedos. Destas 274 vinícolas, efetuou-se uma consulta detalhada sobre cada uma, verificando-se junto à Secretaria da Fazenda se elas se encontravam ativas, e também informações referentes à sua localização para verificar se estavam realmente localizadas dentro da área geográfica delimitada da D.O. Vale dos Vinhedos. Após esse levantamento restaram 21 vinícolas. A partir deste número de vinícolas foi definido o tamanho da amostra, conforme Equação 1, assumindo-se um erro máximo de $5 \%$, um nível de confiança de $95 \%$ e uma porcentagem na qual o fenômeno se verifica de $50 \%$, sendo que não se conhece a porcentagem de adotantes da VP na D.O. Vale dos Vinhedos.

$$
n=\frac{\sigma^{2} p \cdot q \cdot N}{e^{2}(N-1)+\sigma^{2} p \cdot q}
$$

Onde:

$n=$ tamanho da amostra

$\sigma^{2}=$ Nível de confiança expresso em número de desvios-padrão

$p=$ Percentagem com a qual o fenômeno se verifica

$q=$ Percentagem complementar

$N=$ Tamanho da população

$e^{2}=$ Erro máximo permitido

Dessa forma, o tamanho de amostra definido foi de 20 vinícolas, optando-se pela aplicação do estudo a totalidade das vinícolas (21).

No presente estudo foi utilizada como técnica de investigação um questionário semi-estruturado, composto por um conjunto de questões abertas, fechadas e em escala de Likert de 5 pontos, conforme (Anexo A). O questionário aplicado continha questões quanto ao perfil socioeconômico (sexo, idade, escolaridade), quanto a relação com a viticultura (tempo de trabalho, área total da propriedade, área de vinhedos, cultivares, assistência técnica, destinação das uvas, uso de Indicações Geográficas, declividade das áreas de cultivo, mecanização), quanto ao conhecimento sobre a viticultura de precisão (fonte de informação, benefícios, pretensão de uso, barreiras para adoção), e quanto a adoção da tecnologia (técnicas/ferramentas utilizadas, cultivares, benefícios, dificuldades).

Os questionários foram encaminhados às 21 vinícolas no período de novembro a dezembro de 2017. Nesta etapa foi realizado o contato prévio e encaminhados via e-mails aos representantes das vinícolas da região geográfica delimitada da Denominação de Origem Vale dos Vinhedos. Após, foi aplicado o questionário via google forms, sendo que a taxa de retorno obtida através do questionário on-line foi calculada através do número de questionários respondidos via essa ferramenta. Para as vinícolas não respondentes, o questionário foi aplicado diretamente aos representantes das vinícolas da listagem inicial, em forma de entrevista.

Os dados levantados através dos questionários foram analisados com suporte dos softwares "Microsoft Excel" e SPSS (Statistical Package for the Social Science). As variáveis quantitativas foram submetidas a análise estatística descritiva e teste de $t$-Student a $5 \%$ de probabilidade de erro para identificar 
diferenças estatísticas significativas entre os respondentes que declararam conhecer a viticultura de precisão (VP) e os que declararam não conhecer a tecnologia, e entre os adotantes e não adotantes de VP. As variáveis qualitativas foram analisadas em termos de percentagem de respondentes por declaração.

\section{Resultados e discussões}

\subsection{Viticultura de Precisão}

No intuito de diagnosticar o estado de difusão da viticultura de precisão na região delimitada da D.O. Vale dos Vinhedos, os respondentes dessa pesquisa foram questionados se conheciam ou não a VP. Um total de 15 respondentes, representando 71,43\% dos viticultores, declararam conhecer a VP, enquanto que $28,57 \%$ declararam não conhecer a tecnologia. Destes, todos afirmaram ter interesse em conhecer a tecnologia.

Quanto à relação entre a escolaridade e o fato de conhecer ou não a VP, observou-se que $66,67 \%$ dos respondentes que declararam conhecer a VP possuem Ensino Superior completo, $73,34 \%$ quando englobados os que possuem Ensino Superior incompleto $(6,67 \%)$ e $80,01 \%$ quando incluídos os que possuem pós-graduação $(6,67 \%)$. Enquanto, dentre os que não conhecem VP, este percentual é de apenas 50\% (Figura 1).

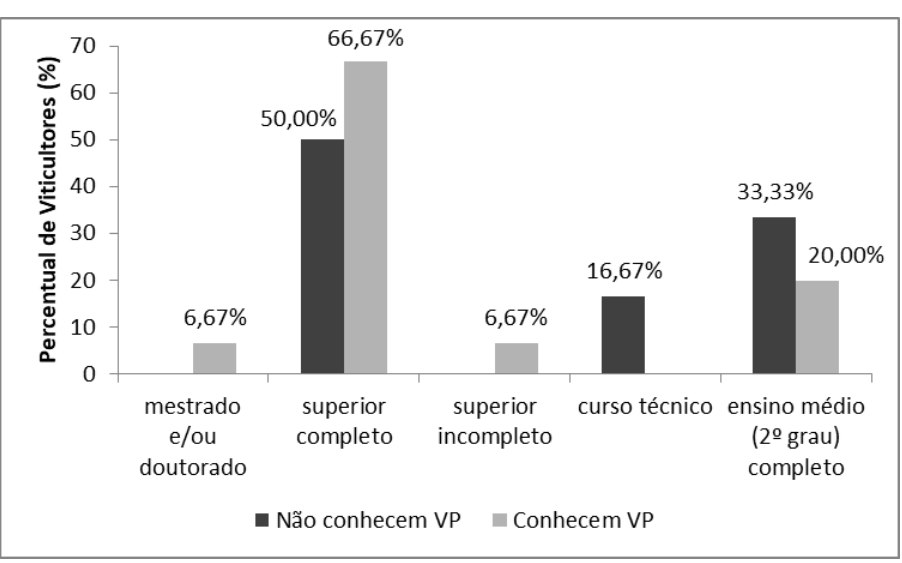

Figura 1 - Percentual (\%) de viticultores que conhecem e não conhecem a VP e seu respectivo nível de escolaridade.

Corroborando esse comportamento, Rogers [13] destaca que os produtores que apresentam escolaridade superior estariam predispostos a adotar inovações mais rapidamente, diferentemente daqueles com nível de escolaridade inferior. Bernardi e Inamasu [14], em estudo sobre adoção de AP em diversas regiões do Brasil, afirmaram que havia uma tendência de elevação do grau de escolaridade dos produtores adotantes de AP quando comparados aos produtores não adotantes.

As médias de idade e tempo de trabalho com viticultura dos que conhecem VP e não conhecem VP foram comparadas, evidenciando que não há diferença significativa entre os grupos, sendo que em média, os que conhecem VP possuem 40,67 anos e os que não conhecem VP tem 48,33 anos, com um desvio-padrão de 9,35 e 9,09 anos respectivamente.

Quanto ao tempo de trabalho com viticultura, verificou-se que os que conhecem VP têm, em média, 24,85 anos de trabalho na atividade e os que não conhecem VP, tem 30,83 anos de envolvimento, com um desvio-padrão de 7,89 e 15,29 anos, respectivamente. Os valores médios de idade e tempo de trabalho com viticultura dos que conhecem e dos que não conhecem VP encontram-se demonstrados na Figura 2.

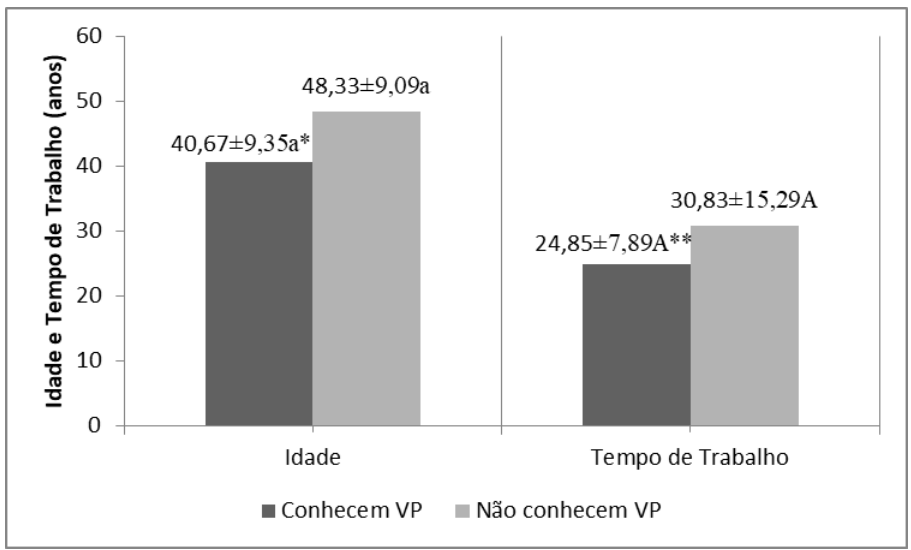

*Letras minúsculas distintas indicam diferença estatística significativa pelo teste de t-Student para $\mathrm{P}<0,05$.

${ }^{* *}$ Letras maiúsculas distintas indicam diferença estatística significativa pelo teste de t-Student para $\mathrm{P}<0,05$

Figura 2 - Média e desvio-padrão de idade e tempo de trabalho

D'Souza et al. [15] afirmaram que produtores mais jovens são mais facilmente atraídos por inovações e, serão, provavelmente, os primeiros a adotar novas tecnologias. Corroborando essa afirmação, Roberts et al. [16] relataram que existe menor probabilidade de adoção de AP pelos produtores mais velhos. Além destes, Charness e Boot [17] e Czaja et al. [18], em pesquisas relacionadas a adoção de tecnologia de informação, encontraram relação inversa entre a idade e a adoção de tecnologias.

Analisando-se o tamanho da propriedade e área destinada à viticultura entre os que conhecem VP e os que não conhecem, não foi constatada diferença significativa na área total da propriedade, sendo que as respectivas médias de área total foram de 22,86 e 16,83 hectares, respectivamente. Quanto à área de vinhedos verificou-se o mesmo comportamento, não havendo diferença significativa entre a área média dos vinhedos dos que conhecem VP (18,55 hectares) e dos que não conhecem VP (8,50 hectares).

Quanto à origem da informação sobre Viticultura de Precisão, os viticultores declararam, em 46,67\% dos casos, ter conhecido a VP através de instituições de ensino e/ou pesquisa, seguido da Internet e dos eventos/capacitações/palestras com $20 \%$ dos casos, em 13,33\% através de comerciantes de insumos, 
$13,33 \%$ por meio de viticultores e, na última colocação, $6,67 \%$ por meio de revistas especializadas.

Anselmi [8] relata que a Internet foi a fonte de informação sobre agricultura de precisão mais acessada entre os adotantes da tecnologia no Rio Grande do Sul, seguida pelas conferências e palestras técnicas, empresas de consultoria técnica, vizinhos, fornecedores de máquinas e equipamentos, televisão, revista especializada, universidades e instituições de pesquisa e rádio.

Já Batista [19] relatou que $62 \%$ dos respondentes declararam que a principal fonte de referência sobre AP foi eventos/capacitações e palestras, seguida da consultoria em AP, com 59,5\% dos casos e Internet com 43\%. As instituições de pesquisa foram indicadas em $13,5 \%$ dos casos e, em apenas $11 \%$ dos casos, as revistas especializadas em AP foram indicadas.

Os dados desta pesquisa sugerem que as fontes de informações sobre VP refletem o estado de difusão da tecnologia, sendo que no caso da VP ela se encontra em estado inicial de difusão no Brasil, ainda em fase de estudo por instituições de pesquisa e ensino e com poucos adotantes, porém apresenta como principais fontes de informação as instituições de ensino e/ou pesquisa, a internet e os eventos/capacitação/palestras.

Os cenários relatados por Anselmi [8] e Batista [19] evidenciam a evolução das fontes de informação sobre AP juntamente com a difusão e adoção da tecnologia, sugerindo que o papel das instituições de pesquisa e ensino é ultrapassado à medida que a tecnologia se torna difundida e é adotada pelos produtores.

Outro ponto importante a ser destacado é que nenhum respondente declarou empresas de consultoria em AP como fonte de informação sobre a tecnologia. Isso evidencia o estado de baixa difusão da VP na D.O. Vale dos Vinhedos. No entanto, considerando a evolução das fontes de informação apresentadas por Anselmi [8] e Batista [19], pode-se inferir que a VP seguirá o mesmo caminho à medida que a difusão da tecnologia e o número de adotantes aumentar.

Antolini \& Scare [20] destacam que os produtores que possuem mais acesso a fontes de informação sobre AP tem maior probabilidade de adotar novas tecnologias, considerando que elas elevam o conhecimento sobre o impacto da adoção da tecnologia no negócio do produtor rural. Filho et al. [21] ressaltam que no Brasil, dado o perfil social de um grande número de agricultores, particularmente o baixo nível escolar, o uso de material técnico convencional tem baixa eficácia. Nesse cenário, em algumas regiões do País, a presença de novos atores do setor privado auxilia na difusão de novas tecnologias.

Os entrevistados foram também questionados se conheciam ou não viticultores que fazem uso de ferramentas e técnicas de viticultura de precisão, sendo que $40 \%$ (6) declararam não conhecer nenhum viticultor que faça uso de VP, e 60\% (9) declararam conhecer. Essa informação assume relevância perante o fato de que em muitos locais um importante meio de comunicação difusor de conhecimentos sobre novas tecnologias é a conversa informal entre vizinhos de propriedade [22].
De acordo com Filho et al. [21], num processo de transferência de tecnologias pode-se adotar a estratégia de focar inicialmente os produtores que apresentam experiências bemsucedidas na adoção de inovações, considerando que estes estariam mais propensos à adoção de novas tecnologias e serviriam de agentes propagadores de nova tecnologia para vizinhos e outros produtores da região, sendo que a autoeficácia em relação à nova tecnologia pode ser adquirida através da observação do outro.

\subsection{A percepção da Viticultura de Precisão pelos viticultores}

Dentre os respondentes que declararam conhecer a Viticultura de Precisão, foram abordadas uma série de questões no intuito de conhecer a percepção desses indivíduos sobre a VP. Primeiramente, os respondentes foram questionados quanto aos três principais benefícios da utilização da VP na percepção destes. Os principais benefícios da utilização da VP na percepção dos viticultores estão apresentados na Figura 3.

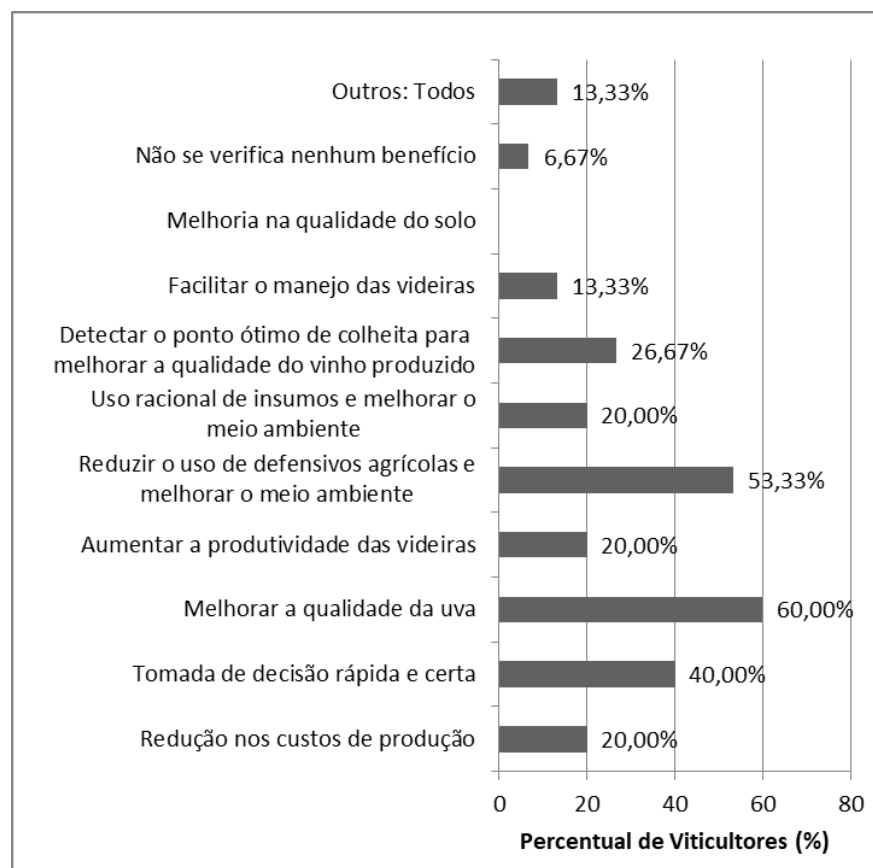

Figura 3 - Principais benefícios da VP na percepção dos viticultores da D.O. Vale dos Vinhedos.

O principal benefício apontado pelos respondentes foi a melhoria na qualidade da uva, em $60 \%$ dos casos, seguido pela redução do uso de defensivos agrícolas para melhoria do meio ambiente com 53,33\% das indicações e tomada de decisão rápida e certa como terceiro benefício mais indicado, com $40 \%$ de apontamentos. 
A percepção dos viticultores da D.O. quanto à importância da melhoria da qualidade das uvas é notável. Segundo Sereno [23], devido ao alto valor agregado que o vinho apresenta e a grande competitividade do mercado global, conhecer as variáveis que afetam a qualidade da uva, e consequentemente do vinho, assume importância primordial entre os viticultores.

Miele et al. [6], salientam que o setor vitivinícola brasileiro busca na VP um meio de melhorar a qualidade de seus produtos e, consequentemente, a competividade do vinho brasileiro, o qual tem sofrido forte concorrência de vinhos importados. Smith [24] ressalta ainda que o preço dos vinhos varia de acordo com a qualidade, assim os viticultores buscam melhorar a produtividade, mas evitando comprometer a qualidade.

É válido destacar que o aumento na produtividade das videiras encontra-se na quinta posição, com $20 \%$ das indicações. À sua frente, com $26,67 \%$ de apontamentos os respondentes indicaram como benefício detectar o ponto ótimo de colheita para melhorar a qualidade do vinho produzido.

Roberts et al. [25], em estudo realizado nos EUA, apontaram o aumento no lucro e os benefícios para o meio ambiente como os principais benefícios da adoção da AP. No entanto, Anselmi [8] salienta que apesar da preservação do meio ambiente estar presente nos debates das questões ligadas ao agronegócio, o aspecto ambiental não é visto pelos agricultores brasileiros com a mesma preocupação que os agricultores europeus e norte-americanos.

Porém, os dados dessa pesquisa apontam que a questão ambiental está entre os principais benefícios da adoção da viticultura de precisão na percepção nos viticultores da D.O. Vale dos Vinhedos, sendo que o segundo benefício mais apontado pelos viticultores foi a redução no uso de defensivos agrícolas e melhoria do meio ambiente $(53,33 \%)$. Nesse sentido, pode-se inferir que há diferença na percepção dos benefícios da tecnologia dependendo da cultura em que é aplicada, considerando que Anselmi [8] realizou seu estudo com produtores de grãos no estado do Rio Grande do Sul.

Em estudo realizado por Artuzo [26], a melhoria do meio ambiente pelo menor uso de insumos foi apontada por $42 \%$ dos produtores de soja adotantes da aplicação a taxa variada. No entanto, esse percentual representou a quarta posição entre as maiores expectativas com a adoção da tecnologia na percepção dos produtores de soja do Rio Grande do Sul.

Outro fato evidenciado neste estudo é a preeminência da qualidade diante da produtividade no cultivo da uva, sendo que a melhoria na qualidade da uva foi o benefício mais indicado pelos respondentes $(60 \%)$, diferentemente do comportamento dos adotantes de agricultura de precisão para outras culturas, como a soja, por exemplo, onde a principal expectativa é o aumento na produtividade da lavoura, conforme descrito por Artuzo [26].

Em relação às técnicas/ferramentas de VP disponíveis, os viticultores foram indagados quanto à pretensão de uso delas em suas propriedades. As ferramentas/técnicas de VP com pretensão de uso pelos viticultores da D.O. Vale dos Vinhedos estão apresentadas na Figura 4.

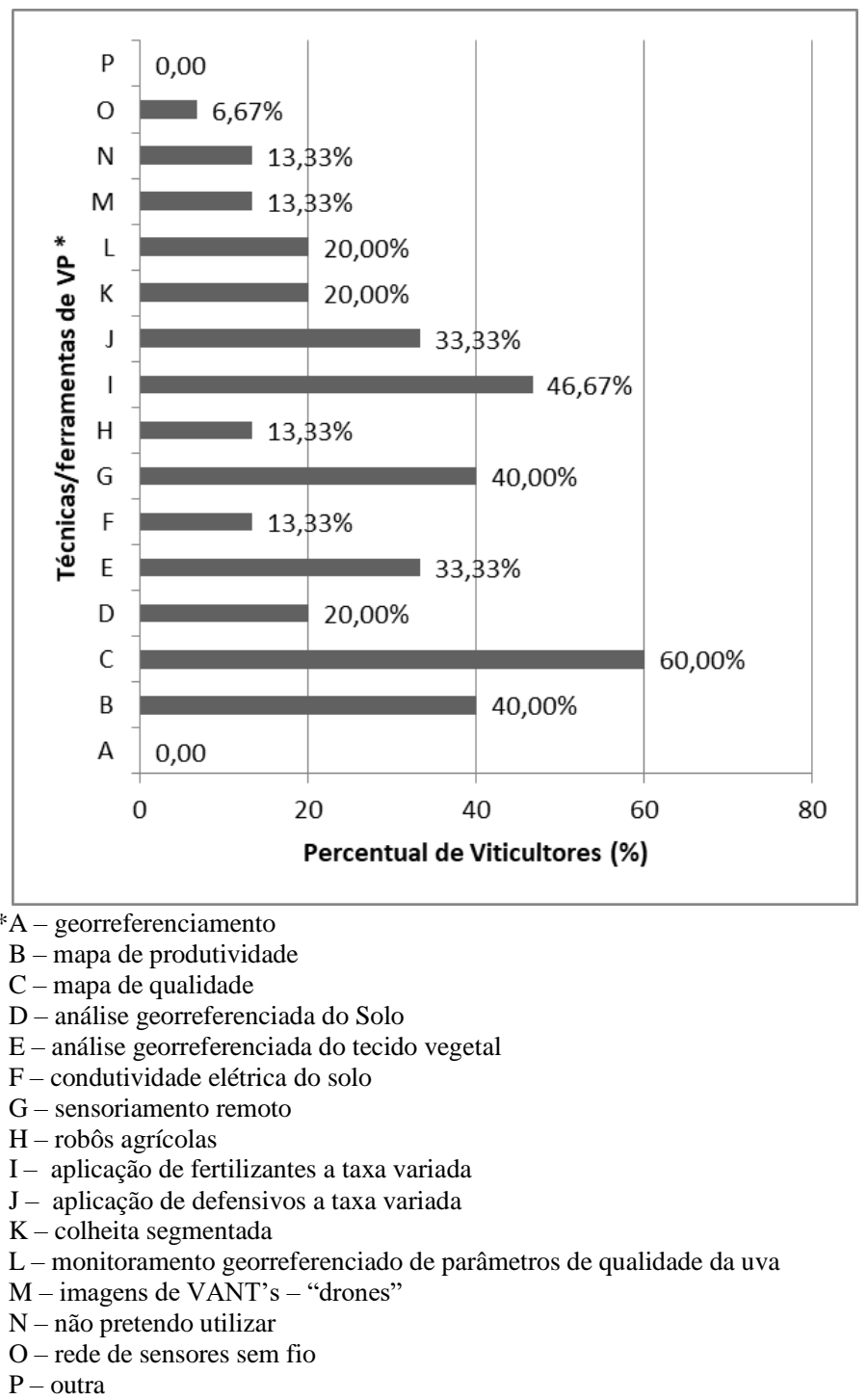

Figura 4 - Ferramentas/técnicas de VP com pretensão de uso pelos viticultores da D.O. Vale dos Vinhedos.

Dentre as técnicas/ferramentas passíveis de utilização, os viticultores indicaram em $60 \%$ dos casos o mapa de qualidade, seguido pela aplicação de fertilizantes a taxa variada com $46,67 \%$ das respostas cada. Na sequência, $40 \%$ dos viticultores declararam que pretendem utilizar o mapa de produtividade e o sensoriamento remoto, sendo que a aplicação de defensivos a taxa variada e análise georreferenciada de tecido vegetal apontou um percentual de $33,33 \%$ cada.

É válido ressaltar que $95,77 \%$ da área dos vinhedos $(1762,48$ hectares) da D.O. Vale dos Vinhedos encontra-se 
georreferenciado. Desse modo, pode-se afirmar que todas as áreas de cultivo de uva abrangidas neste estudo já estão georreferenciadas, justificando a ausência $(0 \%)$ de pretensão de uso do georreferenciamento pelos viticultores (Figura 4). Fialho et al. [27] ressalta que uma boa base de dados georreferenciada permite não só obter informações sobre cada um dos vinhedos, mas a relacionar essas informações espacialmente e possibilitar a combinação com informações de outras bases georreferenciadas.

Assim como evidenciado na percepção dos benefícios de utilização da VP, as ferramentas/técnicas com pretensão de uso pelos viticultores reforça a importância da qualidade da uva na percepção dos viticultores da D.O. Vale dos Vinhedos. Zardo [28] salienta que a elevada variabilidade espacial dos atributos químicos do solo, da produtividade e dos parâmetros enológicos como potencial alcoólico e conteúdo de ácido tartárico existentes em um vinhedo servem de justificativa para o uso da viticultura de precisão, podendo incrementar a produtividade e melhorar a qualidade do mosto da uva quando comparado ao manejo tradicional.

De acordo com Sereno [23], a capacidade que a VP possui de identificar diferentes zonas no vinhedo, com potenciais qualitativos distintos e que origina diferenças na rentabilidade econômica das vinícolas está provada, em vista dos diferentes preços que a uva segmentada e seus vinhos têm. Segundo o autor, esse é o argumento mais robusto que possibilita a VP um futuro promissor a nível mundial.

Em relação às barreiras para utilização da VP na D.O. Vale dos Vinhedos na percepção dos viticultores respondentes, os resultados encontram-se apresentados na Figura 5.

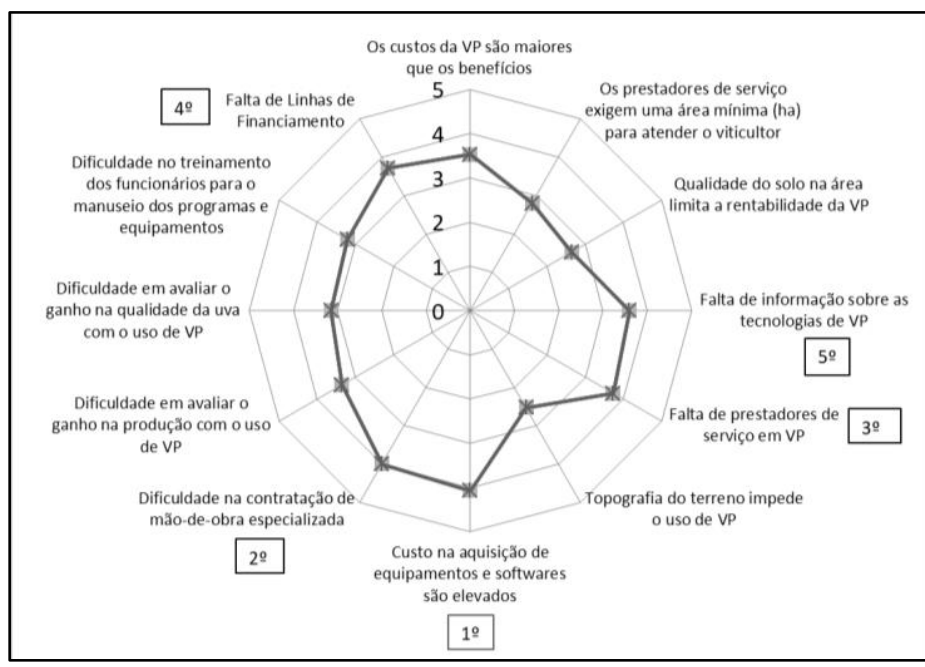

*Valores em escala de Likert de 5 pontos. 5 - concordo totalmente e 1 - discordo totalmente.

Figura 5 - Percepção dos viticultores quanto às barreiras para utilização de VP na D.O. Vale dos Vinhedos.
Através da análise da Figura 5 pode-se ter uma visão mais evidente quanto à percepção das barreiras para utilização da VP na D.O., sendo que as barreiras mais pronunciadas foram o custo elevado para aquisição de equipamentos e softwares (média de 4,07 pontos de concordância), seguida da dificuldade de contratação de mão-de-obra especializada (média de 4 pontos de concordância), da falta de prestadores de serviço em VP (média de 3,73 pontos de concordância), da falta de linhas de financiamento (média de 3,71 pontos de concordância), e da falta de informação sobre tecnologias de VP (média de 3,6 pontos de concordância).

Artuzo [26], em análise das dificuldades de adoção da tecnologia de aplicação a taxa variada no cultivo da soja observou que o comportamento encontrado foi semelhante, sendo que as dificuldades com maior pronunciamento foram o custo elevado da tecnologia, a falta de pessoal qualificado e a falta de informação sobre a tecnologia. No entanto, no estudo do autor, os respondentes discordaram da afirmativa de faltar prestadores de serviço na área, o que se explica devido a maior difusão e consolidação desta tecnologia em áreas produtoras de grãos.

Diferentemente dos prestadores de serviço em agricultura de precisão para culturas de grãos, que se encontram amplamente disseminados no estado, os dados evidenciam a falta de prestadores de serviço em viticultura de precisão na região. Isso se deve possivelmente ao caráter recente de uso de VP não só no estado, mas também a nível mundial, sendo que os primeiros trabalhos foram conduzidos nos EUA e na Austrália há cerca de 20 anos [6]. Enquanto que relatos de aplicação da agricultura de precisão remontam aos anos 1980, há cerca de 38 anos [29].

Anselmi [8], em estudo da adoção de AP no estado do Rio Grande do Sul, verificou que os elevados custos dos equipamentos e a falta de pessoal qualificado dificultam o processo de difusão da AP, impedindo o alcance de taxas de adoção superiores. Corroborando, dessa forma, os resultados de Anselmi [8], Silva et al. [30] e Mattoso e Garcia [31], que apontaram o fator econômico como a principal barreira para a adoção de AP, pois os custos elevados das ferramentas apresentam maior contribuição para a lenta adoção da tecnologia.

Além disso, é válido ressaltar que, na percepção dos viticultores, a topografia do terreno não é considerada uma barreira para utilização da VP, sendo que a média foi de 2,53 pontos, ou seja, tendência à discordância da afirmativa, assim como também não consideram a qualidade do solo como limitante da rentabilidade da VP, considerando que a média foi de 2,64 pontos. Quanto à exigência de área mínima de vinhedo para aplicação da VP, os respondentes demonstraram desconhecer a afirmativa (não concordam e nem discordam $-2,8$ pontos), fato justificado pela concordância com a afirmativa que faltam prestadores de serviço em VP. 


\subsection{Os adotantes de Viticultura de Precisão na D.O. Vale dos Vinhedos}

Dos 21 respondentes apenas 5 se declararam usuários da tecnologia, representando $23,81 \%$ dos viticultores participantes da pesquisa. Destas, quatro estão localizadas no município de Bento Gonçalves e uma no município de Garibaldi.

Todos os adotantes possuem cultivo predominante de uvas viníferas (europeias), sendo que três (60\%) fazem uso da certificação da D.O. Vale dos Vinhedos em seus produtos, um (20\%) faz uso da I.P. Vale dos Vinhedos e um (20\%) não faz uso de nenhuma das Indicações Geográficas. Referente ao nível de escolaridade, 60\% (3) possuem Ensino Superior completo, enquanto que o restante, $40 \%$ (2) possuem apenas o Ensino Médio completo.

Para as variáveis idade, tempo de trabalho com viticultura, tamanho das propriedades e tamanho dos vinhedos dos adotantes e não adotantes e VP não foi constatada diferença estatística significativa. Os dados com os valores médios encontram-se apresentados na tabela 1.

Tabela 1 - Média de Idade, tempo de trabalho com viticultura, área total da propriedade e área de vinhedos dos adotantes e não adotantes de VP.

\begin{tabular}{ccccc}
\hline & $\begin{array}{c}\text { Idade } \\
\text { (anos) }\end{array}$ & $\begin{array}{c}\text { Tempo } \\
\text { Trabalho } \\
\text { (anos) }\end{array}$ & $\begin{array}{c}\text { Área total } \\
\text { (hectares) }\end{array}$ & $\begin{array}{c}\text { Área de } \\
\text { Vinhedos } \\
\text { (hectares) }\end{array}$ \\
\hline Adotantes & $41,75 \mathrm{a}$ & $28,00 \mathrm{~b}$ & $31,34 \mathrm{c}$ & $29,00 \mathrm{~d}$ \\
Não adotantes & $49,71 \mathrm{a}$ & $33,19 \mathrm{~b}$ & $15,65 \mathrm{c}$ & $9,21 \mathrm{~d}$ \\
\hline
\end{tabular}

Letras iguais na coluna indicam a não existência de diferença significativa pelo teste de $\mathrm{t}$-Student para $\mathrm{p}<0,05$.

Os dados de área de aplicação de VP entre os respondentes remontaram a um total de 139 hectares, o que representa $7,55 \%$ da área total de vinhedos da D.O. Vale dos Vinhedos, e $42,21 \%$ da área total de vinhedos dos participantes desta pesquisa. Analisando a área de utilização de VP nas propriedades adotantes, foi verificado que os viticultores aplicam VP em 77,69\% da área total de suas propriedades e em $85,43 \%$ da área de vinhedos, em média. Anselmi [8] relatou que, em média, a AP é aplicada em $72 \%$ da área da propriedade, em estudo da aplicação de AP em cultivo de grãos.

A partir da análise das tecnologias adotadas pelos viticultores, verificou-se que $100 \%$ (5) possuem os vinhedos georreferenciados, $80 \%$ (4) fazem uso de mapas de qualidade, mapa de produtividade e aplicação de fertilizantes a taxa variada, $60 \%$ (3) fazem uso de análise georreferenciada do solo, aplicação de defensivos a taxa variada e colheita segmentada e $20 \%$ (1) faz uso de monitoramento georreferenciado de parâmetros de qualidade da uva (Figura 6).

De acordo com Braga [32], a colheita segmentada tem sido uma das aplicações mais adotadas da VP em Portugal, especificamente quando usado como recurso de decisão mapas de Normalized Difference Vegetation Index (NDVI) referente a área de sensoriamento remoto. No entanto, a aplicação de VP com maior taxa de adoção é a condução assistida por GPS (lightbar ou barra de luzes).

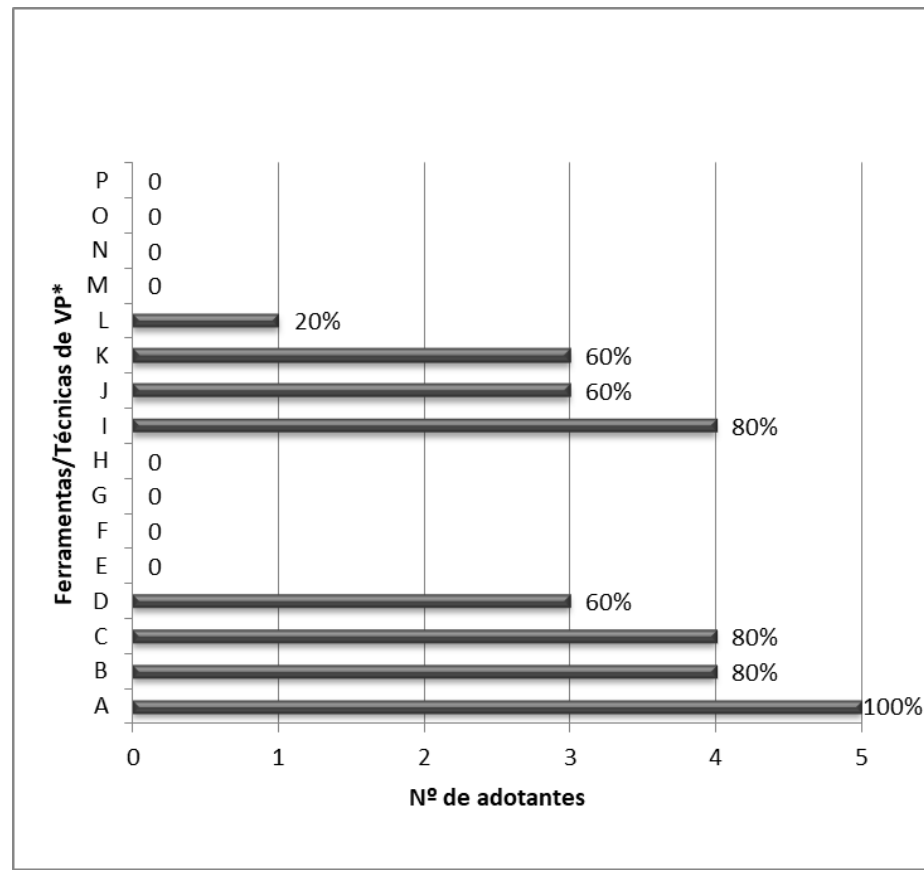

*A - georreferenciamento

$\mathrm{B}$ - mapa de produtividade

$\mathrm{C}$ - mapa de qualidade

D - análise georreferenciada do Solo

E - análise georreferenciada do tecido vegetal

$\mathrm{F}$ - condutividade elétrica do solo

$\mathrm{G}$ - sensoriamento remoto

$\mathrm{H}$ - robôs agrícolas

I - aplicação de fertilizantes a taxa variada

J - aplicação de defensivos a taxa variada

$\mathrm{K}$ - colheita segmentada

$\mathrm{L}$ - monitoramento georreferenciado de parâmetros de qualidade da uva

M - imagens de VANT's - "drones"

$\mathrm{N}$ - não pretendo utilizar

$\mathrm{O}$ - rede de sensores sem fio

$\mathrm{P}-$ outra

Figura 6 - Ferramentas/técnicas de VP adotadas pelos viticultores da D.O. Vale dos Vinhedos.

Anselmi [8] relatou que na cultura da soja no estado do Rio Grande do Sul, as ferramentas mais adotadas foram a amostragem georreferenciada de solo, a aplicação a taxa variada e a barra de luzes. Bernandi e Inamasu [14] corroboram relatando que a barra de luzes e piloto automático para aplicação de insumos a taxa variada são os equipamentos mais utilizados nas propriedades adotantes de AP no Brasil.

Filho e Cunha [33], em pesquisa da adoção de AP na região sudoeste de Goiás, apontam que as ferramentas e técnicas mais utilizadas foram a amostragem georreferenciada do solo e a aplicação de sólidos a taxa variada. Segundo Batista [19], algumas tecnologias de AP bastante difundidas em países europeus e nos 
EUA, tais como uso de sensores em tempo real, imagens aéreas ou orbitais, uso de VANT's e telemetria, apresentam baixos índices de adoção no Brasil.

Os dados apontam para um grande gargalo na aplicação da agricultura de precisão na viticultura brasileira, traçando um cenário favorável às empresas prestadoras de serviços em AP, considerando a vasta gama de técnicas e ferramentas disponíveis e que se apresentam com baixa difusão entre os viticultores da D.O. Vale dos Vinhedos.

Quando questionados se o uso da VP tem reduzido os custos de produção da uva, $40 \%$ (2) declararam que houve redução nos custos de produção, mas não sabiam especificar o quanto, $40 \%$ (2) declararam que não houve redução e os custos mantiveram-se os mesmos, e $20 \%$ (1) declarou que houve aumento nos custos de produção. Artuzo [26] e Werner [34], em análise comparativa do cultivo da soja com AP e sem a tecnologia verificaram uma redução dos custos de produção da cultura.

Quanto à produtividade, $80 \%$ (4) declararam que não houve aumento na produtividade e apenas $20 \%$ dos adotantes (1) declarou que houve aumento na produtividade, mas não sabia especificar o quanto. Quanto à qualidade, todos declararam que houve melhoria na qualidade da uva com a utilização da VP. Dados quanto à percepção dos viticultores referentes à melhoria na qualidade da uva e aumento de produtividade em videiras com o uso de VP não foram encontrados.

Os adotantes de VP foram submetidos à análise de afirmações quanto às dificuldades de uso da VP em sua percepção. Os resultados apresentam-se demonstrados na Figura 7.

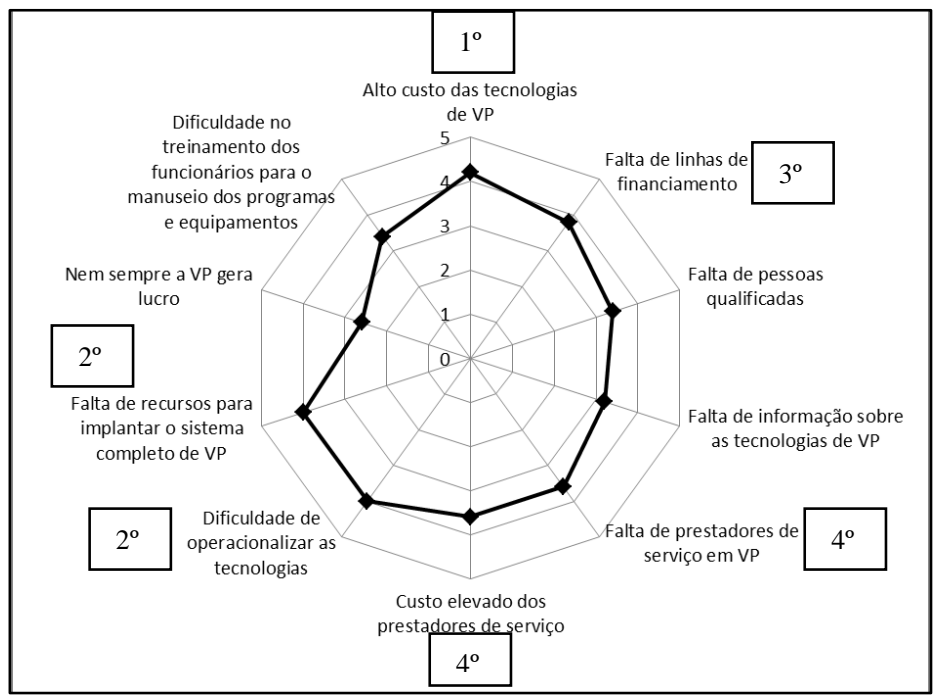

*Valores em escala de Likert de cinco pontos. 5-concordo totalmente e 1-discordo totalmente.

Figura 7 - Dificuldades de uso da VP na percepção dos adotantes da tecnologia na D.O. Vale dos Vinhedos.
Na Figura 7 é possível verificar que a maior dificuldade apontada pelos adotantes de VP foi o alto custo das tecnologias de VP, com uma média de concordância de 4,2, seguida da dificuldade de operacionalizar as tecnologias e da falta de recursos para implantar o sistema completo de VP, com uma média de concordância de 4 pontos. Além destes, aparecem com maior relevância à falta de linhas de financiamento $(3,8)$, e a falta de prestadores de serviço em VP, assim como o custo elevado destes $(3,6)$.

Artuzo [26] obteve resultados semelhantes para as dificuldades de uso da tecnologia de aplicação a taxa variada (ATV) na percepção dos produtores do Rio Grande do Sul. Na ocasião, o autor relatou uma média de concordância de 4,52 para a falta de informação sobre a tecnologia de ATV, 4,41 para a falta de pessoal qualificado, 4,10 para os custos das tecnologias de ATV e 4,04 para o custo elevado dos prestadores de serviço.

\section{Conclusões}

Os cinco viticultores identificados como adotantes de VP indicaram como principais benefícios do uso da VP a melhoria na qualidade da uva, a redução do uso de defensivos agrícolas e a tomada de decisão rápida e certa. As principais ferramentas e técnicas apontadas como pretensão de uso futuro pelos viticultores foram o mapa de qualidade e produtividade, a aplicação de fertilizantes e defensivos a taxa variada, e a análise georreferenciada de tecido vegetal. Por sua vez, o custo elevado para aquisição de equipamentos e softwares, a dificuldade de contratação de mão-de-obra especializada, a falta de prestadores de serviço em VP e a falta de informação sobre tecnologias de VP foram as barreiras apontadas para utilização da VP. Dentre as técnicas e ferramentas de VP adotadas na D.O Vale dos Vinhedos estão o georreferenciamento, os mapas de qualidade e produtividade, a aplicação de fertilizantes a taxa variada, a análise georreferenciada do solo, a aplicação de defensivos a taxa variada, a colheita segmentada e o monitoramento georreferenciado de parâmetros de qualidade da uva. Sugere-se para trabalhos futuros a realização de um diagnóstico mais amplo, abrangendo outras regiões a fim de identificar a adoção da VP na cadeia vitivinícola do estado.

\section{Agradecimentos}

Ao IBRAVIN, à APROVALE e a EMBRAPA pelo auxílio e orientação. A Universidade Federal do Pampa (UNIPAMPA), e ao Programa de Pós-Graduação em Agricultura de Precisão (PPGAP) da Universidade Federal de Santa Maria. 


\section{DIAGNOSIS OF THE ADOPTION OF PRECISION VITICULTURE IN VALE DOS VINHEDOS - RIO GRANDE DO SUL}

ABSTRACT: In viticulture, the use of precision agriculture (AP) techniques, named in this case precision viticulture (VP), is considered relatively recent. In this sense, the present work sought to diagnose the adoption of VP tools and techniques by winegrowers from the Denomination of Origin Vale dos Vinhedos, located in the state of Rio Grande do Sul - Brazil. The research was exploratory and descriptive, making use of qualitative and quantitative analysis techniques. Data were collected through the application of 21 questionnaires to the winery representatives of the region. Only 5 (23.81\%) winegrowers were identified as VP, evidencing the low rate of adoption of the technology in the region. Among the techniques and tools of the VP adopted in the Denomination of Origin Vale dos Vinhedos are the georeferencing of the areas, the maps of quality and productivity, the application of fertilizers at varied rates, the georeferenced soil analysis, the application of pesticides at a varied rate, the segmented harvest and the georeferenced monitoring of grape quality parameters. As difficulties in using VP technology, the main ones were the high cost and difficulty of operationalizing the technologies, the lack of resources to implement the complete system and financing lines, as well as the lack of service providers, and the cost of these. The low rate of adoption of this technology reflects the incipient diffusion of this technology among the region's winegrowers.

Keywords: Precision Agriculture. Vitis vinifera. Denomination of Origin. Adoption of technologies.

\section{Referências}

[1] LEEUWEN, C.; SEGUIN, G. The concept of terroir in viticulture. Journal of Wine. Research, v. 17, n. 1, p. 1-10, 2006.

[2] IBGE - Instituto Brasileiro de Geografia e Estatística. Sistema IBGE de Recuperação Automática - $\quad$ SIDRA. Disponível em: https://sidra.ibge.gov.br/tabela/1618. Acesso em: 11 jan. 2018.

[3] MELLO, L. M. R.; MACHADO, C. A. E. Cadastro Vitícola Georreferenciado da Denominação de Origem. Loiva Maria Ribeiro de Mello, Carlos Alberto Ely Machado, editores técnicos. Brasília, DF: Embrapa, 2015.

[4] TONIETTO, J.; ZANUS, M. C.; FAlCADE, I.; GUERRA, C. C. O regulamento de uso da denominação de origem Vale dos Vinhedos: vinhos finos tranquilos e espumantes. Bento Gonçalves: Embrapa Uva e Vinho, 35 p. 2013.

[5] MIELE, A.; FLORES, C. A.; ALBA, J. M. F. Status atual da pesquisa de viticultura de precisão no Rio Grande do Sul: primeiros resultados da UP Uva para Vinho. Agricultura de Precisão: um novo olhar. Embrapa Instrumentação. p. 266272. 2011.
[6] MIELE, A.; FLORES, C. A.; ALBA, J. M. F. Efeito da variabilidade espacial de solos do Vale dos Vinhedos na composição do vinho Merlot - Safra 2012. Agricultura de Precisão: resultados de um novo olhar. p. 361 - 367. 2014

[7] ESSER, A. A.; ORTEGA BLU, R. Aplicaciones de la viticultura de precisión en Chile: Estudio de casos. Agronomía y Forestal, Santiago, v. 5, n. 17, p.17-21, mayo/jun., 2002

[8] ANSELMI, A. A. Adoção da agricultura de precisão no Rio Grande do Sul. 2012. 105 p. Dissertação (Mestrado em Agronegócio) - Universidade Federal do Rio Grande do Sul, Porto Alegre, 2012.

[9] BOMBÍN, J. Y. Viticultura de precisión: Introducción y objetivos. Viticultura de precisión. VIII Encuentro Técnico, Madrid, 2013. p.17-25. 2013.

[10] MATESE, A.; VACCARI, F.P.; TOMASI, D.; GENNARO, S.F.D.; PRIMICERIO, J.; SABATINI, F. E GUIDONI, S. CrossVit: Enhancing Canopy Monitoring Management Practices in Viticulture. Sensors, vol. 13, n. 6, p. 7652 7667. 2013

[11] BRAMLEY, R. G. V., \& HAMILTON, R. P. Hitting the zone-making viticulture more precise. In Proceedings of the 12th Australian Wine Industry Technical Conference. Eds. RJ Blair, PJ Williams and IS Pretorius (AWITC: Adelaide), p. 57-61. 2005.

[12] TISSEYRE, B.; TAYLOR, J. An overview of methodologies and technologies for implementing precision agriculture in viticulture. In: CONGRESSO BRASILEIRO DE VITICULTURA E ENOLOGIA. 12., 2008. Bento Gonçalves. Anais... Bento Gonçalves: EMRAPA, CNPUV, p. 45. 2008.

[13] ROGERS, E. M. Elements of diffusion. Diffusion of innovations, v.5 p. 1-38, 2003.

[14] BERNARDI, A. C. C.; INAMASU, R. Y. Adoção da agricultura de precisão no Brasil. Agricultura de Precisão: resultados de um Novo Olhar. EMBRAPA. p. 559-577. 2014

[15] D'SOUZA, G.; CYPHERS, D.; PHIPPS, T. Factors affecting the adoption of sustainable agricultural practices. Agricultural and Resource Economics Review, Ithaca, v. 22, n. 2, 9. p.159-165, 1993.

[16] ROBERTS, R. K.; ENGLISH, B.C.; LARSON, J. A.; COCHRAN, R. L.; GOODMAN, W. R.; LARKIN, S. L.; MARRA, M. C.; MARTIN, S. W.; SHURLEY, W. D.; REEVES, J. M. Adoption of site-specific information and variable rate technologies in cotton precision farming. Journal of Agricultural and Applied Economics, v. 36, n. 1, p. 143-158, 2004.

[17] CHARNESS, N.; BOOT, W. R. Aging and information technology use: potential and barriers. Current Directions in Psychological Science, New York, v. 18 , n. 5, p. 253-258, 2009.

[18] CZAJA, S. J.; FISK, A. D.; HERTZOG, C.; ROGERS, W. A.; CHARNESS, N.; NAIR, S. N.; SHARIT, J. Factors predicting the use of technology: findings from the Center for Research and Education on Aging and Technology Enhancement (Create). Psychology and aging, Washington, DC, v. 21, n. 2, p. 333$352,2006$.

[19] BATISTA, J. A. Adoção da agricultura de precisão na Amazônia: estudo de caso a região cone sul do estado de Rondônia. 2016. 85 p. Dissertação (Mestrado Profissionla em Agricultura de Precisão) - Universidade Federal de Santa Maria, Santa Maria, 2016.

[20] ANTOLINI, L. S.; SCARE, R. F. Condicionantes de adoção de inovações e tecnologias de AP por produtores rurais: revisão sistemática de literatura e oposição de um modelo conceitual. Artigo. $11^{\circ}$ Convibra - Administração, 2014.

[21] FILHO, H. M. S.; BUAINAIN, A. M.; SILVEIRA, J. M. F. J.; VINHOLIS, M. M. B. Condicionantes da adoção de inovações tecnológicas na agricultura. Cadernos de Ciência \& Tecnologia, Brasília, v. 28, n.1, p.223-255, jan/abr. 2011. 


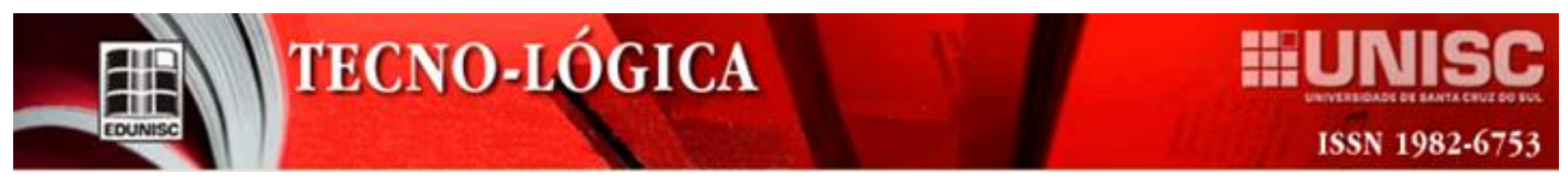

[22] VANZELA, L. S.; HERNANDEZ, F. B.; DOURADO, L. A. C.; MAURO, F. Tendência de adoção de tecnologias por parte dos irrigantes do cinturão verde em Ilha Solteira - SP. XXXII Congresso Brasileiro de Engenharia Agrícola CONBEA 2003. Goiânia - GO. 2003.

[23] SERENO, P. M. V. M. Viticultura de Precisão: utilização da detecção remota no estudo da variabilidade espacial do vigor, produção, qualidade, castas "Syrah" e "Touriga Franca". 2009. 84 p. Dissertação (Mestrado em Viticultura e Enologia) - Instituto Superior de Agronomia, Lisboa, Portugal, 2009.

[24] SMITH, F. Precision Viticulture. Australian Grapegrower and Winemaker, 468, p. 31-33. 2003.

[25] ROBERTS, R. K. et al. Precision farming by cotton producers in six southern states: results from the 2001. Southern precision farming survey. 81 p. 2001.

[26] ARTUZO, F. D. Análise da eficiência técnica e econômica da agricultura de precisão a taxa variável de fertilizantes na cultura da soja no RS. 2015.113 p. Dissertação (Mestrado em Agronegócios) - Universidade Federal do Rio Grande do Sul, Porto Alegre, 2015.

[27] FIALHO B, F. ; MEllo, L. M.; GUZZO, L. C. Metodologia de Georreferenciamento do Cadastro Vitícola. Bento Gonçalves: EMBRAPA-UVA E VINHO. 26p. (Documentos, 50). 2005.

[28] ZARDO, K. Vitivinicultura de Precisão aplicada a produção e qualidade de uva Pinot Noir no Rio Grande do Sul. 2009. 98 p. Dissertação (Mestrado em Engenharia Agrícola) - Universidade Federal de Santa Maria, Santa Maria, RS. 2009.

[29] BRASIL. Ministério da Agricultura, Pecuária e Abastecimento. Agricultura de Precisão - Boletim Técnico. Ministério da Agricultura, Pecuária e Abstecimento. Secretaria de Desenvolvimento Agropecuário e Cooperativismo. Brasília: MAPA/ACS, 36p. 2013.

[30] SILVA, C.; DE MORAES, M.; MOLIN, J. Adoption and use of precision agriculture Technologies in the sugarcane industry of São Paulo state, Brazil. Precision Agiculture, Berlin, v. 12, n. 1, p. 67-81, 2011.

[31] MATTOSO, M. J.; GARCIA, J. C. Análise econômico da agricultura de precisão. In: congresso brasileiro de agricultura de precisão, 2. 2006. São Pedro. Anais... 1 cd-ROM. Piracicaba: USP/ESALQ, 2006.

[32] BRAGA, R. Entrevista a Ricardo Braga. [Entrevista disponibilizada em 14 de setembro de 2014]. Disponível em: <http://www.agronegocios.eu/noticias/entrevista-a-ricardo-braga/>. Entrevista concedia a Margarida Matos. Acesso em: 28 dez. 2017.

[33] FILHO, R. S.; CUNHA, J. P. A. R. Agricultura de precisão: particularidades de sua adoção no sudoeste de Goiás - Brasil. Eng. Agric., Jaboticabal, v.35, n. 4, p.689-698, jul/ago. 2015.

[34] WERNER, V. Análise econômica e experiência comparativa entre agricultura de precisão e tradicional. 2007. 134p. Tese (Doutorado em Mecanização Agrícola) -Universidade Federal de Santa Maria, Santa Maria, RS, 2007. 


\section{ANEXO A - QUESTIONÁRIO APLICADO AOS VITICULTORES}

\section{O viticultor do Vale dos Vinhedos e a viticultura de precisão}

1. Nome (opcional):

2. Número Cadastro Vitícola (opcional):

3. E-mail (opcional):

$\begin{array}{lll}\text { 4. Gênero: } & \text { ( ) } \mathrm{M} & \text { ( ) } \mathrm{F}\end{array}$

5. Idade:

6. Cidade:

( ) Bento Gonçalves

( ) Garibaldi

( ) Monte Belo do Sul

7. Escolaridade:

( ) sem escolaridade

( ) ensino fundamental $\left(1^{\circ}\right.$ grau $)$ incompleto

( ) ensino fundamental ( $1^{\circ}$ grau $)$ completo

( ) ensino médio $\left(2^{\circ}\right.$ grau $)$ incompleto

( ) ensino médio ( $2^{\circ}$ grau) completo

( ) curso técnico.

( ) superior incompleto

( ) superior completo.

( ) mestrado ou doutorado.

8. Há quanto tempo trabalha com viticultura?

9. Qual a área (ha) total da sua propriedade?

10. Quantos membros a família trabalham na propriedade:

11. Você tem outra fonte de renda além da viticultura?

( ) Sim ( ) Não

12. Qual a área (ha) cultivada com videiras na propriedade?

13. Em sua propriedade predomina o cultivo de Uvas Viníferas (europeias) ou de Uvas Americanas e híbridas? Uvas viníferas (eutopeias) - Vitis vinífera : Ex.:Cabernet Sauvignon, Merlot, Cabernet Franc, Tannat, Pinot Noir, Syrah, Alicante Bouschet, Tempranillo, Moscato Branco, Riesling Itálico, Chardonnay, Prosecco.. entre outras.

Uvas

americanas/híbridas - Ex.: Isabel, Bordô, Concord, Jacquez, Herbemont, Cynthiana, Niágara Branca, Niágara Rosada, Couderc 13, Moscato Embrapa, BRS Lorena, Seyval... entre outras

( ) Uvas viníferas (europeias)

( ) Uvas americanas e híbridas

( ) Outros:

14. Possui assistência técnica?

( ) Engenheiro Agrônomo com dedicação exclusiva

( ) Engenheiro Agrônomo externo (Empresas, Cooperativas, Associações...)

( ) Técnico Agrícola com dedicação exclusiva

( ) Técnico Agrícola externo (Empresas, Cooperativas, Associações...)

( ) Enólogo com dedicação exclusiva

( ) Enólogo externo (Empresas, Cooperativas, Associações...)

( ) Técnico em Viticultura e/ou Enologia com dedicação exclusiva

( ) Técnico em Viticultura e/ou Enologia externo (Empresas, Cooperativas, Associações...)

( ) Não

( ) Outro:

15.

Qual a destinação das uvas produzidas em sua propriedade?

( ) Finalidade 1. Vinificação terceiros (cantinas): Uva vendida para empresas processadoras de uvas para elaboração de vinhos, sucos e derivados.
( ) Finalidade 2. Vinificação na própria indústria: Uva produzida e processada pela própria empresa.

( ) Finalidade 3. Vinificação própria cantina rural: Uva produzida e processada pela cantina rural

( ) Finalidade 4. Vinho para consumo: Uva usada pelo produtor para elaborar vinho para o consumo da própria família.

( ) Finalidade 5. Venda in natura: uva vendida para ser consumida in natura.

( ) Finalidade 6. Venda para doces: Venda para empresas que elaboram doces, geleias, etc..

( ) Finalidade 7. Venda para outros produtores: Venda para uma pessoa física para elaboração de vinho colonial.

( ) Finalidade 8. Consumo próprio: Uva consumida na propriedade para consumo in natura, elaboração de doces, doações...

16. Seus produtos são comercializados com a certificação da Denominação de Origem (DO) ou Indicação de procedência (IP) Vale os Vinhedos?

( ) Não.

( ) Sim. D.O. Vale dos Vinhedos

( ) Sim. I.P. Vale dos Vinhedos

( ) Outros:

17. Qual a classe e declividade predominante na área cultivada com videira em sua propriedade?

( ) Plano (de 0 a $3 \%$ de declive)

( ) Suave-ondulado (3 a $8 \%$ )

( ) Ondulado ( 8 a $20 \%)$

( ) Forte-ondulado (20 a $45 \%)$

( ) Montanhoso (45 a 75\%)

( ) Forte-Montanhoso (>75\%)

18. Quais as etapas do manejo da videira que faz uso de mecanização? Assinale quantas forem necessárias.

( ) Poda seca

( ) Adubação

( ) Aplicação de defensivos

( ) Poda Verde

( ) Colheita

( ) Nenhuma

( ) Outros:

Viticultura de precisão: você conhece?

Nesta seção as perguntas referem-se a Viticultura de Precisão (Agricultura de Precisão aplicada na Viticultura) e o seu conhecimento quanto a tecnologia.

19. Você conhece a Viticultura de Precisão?

( ) $\operatorname{Sim} \quad$ ( ) Não

20. Você tem interesse em conhecer a Viticultura de Precisão?
( ) $\mathrm{Sim}$
( ) Não
( ) Já conheço

Viticultura de precisão: qual a sua relação com a tecnologia?

Nesta secção as perguntas referem-se a Viticultura de Precisão e a sua relação com esta tecnologia, buscando conhecer sua opinião e percepção quanto ao seu uso.

21. Você conhece algum viticultor que faz uso de técnicas/ferramentas de Viticultura de Precisão (VP)?

( ) Sim

( ) Não

22. Como você conheceu a Viticultura de Precisão?

( ) Revista especializada em Agricultura de Precisão (AP) 


\begin{tabular}{|c|c|c|c|c|c|}
\hline \multirow[b]{2}{*}{ Problemas } & \multicolumn{5}{|c|}{ Nível de Concordância } \\
\hline & 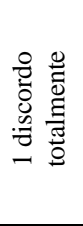 & 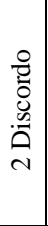 & 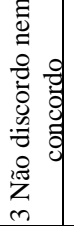 & 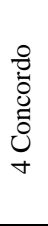 & 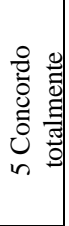 \\
\hline $\begin{array}{l}\text { Os custos da VP são maiores que o } \\
\text { benefícios }\end{array}$ & & & & & \\
\hline $\begin{array}{l}\text { Os prestadores de serviço exigem u } \\
\text { área mínima (ha) para atender o } \\
\text { viticultor }\end{array}$ & & & & & \\
\hline $\begin{array}{l}\text { Qualidade do solo na área limita a } \\
\text { rentabilidade da VP }\end{array}$ & & & & & \\
\hline $\begin{array}{l}\text { Falta de informação sobre as tecno } \\
\text { de VP }\end{array}$ & & & & & \\
\hline Falta de prestadores de serviço em & & & & & \\
\hline $\begin{array}{l}\text { Topografia do terreno impede o us } \\
\text { VP }\end{array}$ & & & & & \\
\hline $\begin{array}{l}\text { Custo na aquisição de equipamento } \\
\text { softwares são elevados }\end{array}$ & & & & & \\
\hline $\begin{array}{l}\text { Dificuldade na contratação de mão } \\
\text { obra especializada }\end{array}$ & & & & & \\
\hline $\begin{array}{l}\text { Dificuldade em avaliar o ganho na } \\
\text { produção com o uso de VP }\end{array}$ & & & & & \\
\hline $\begin{array}{l}\text { Dificuldade em avaliar o ganho na } \\
\text { qualidade da uva com o uso de VP }\end{array}$ & & & & & \\
\hline $\begin{array}{l}\text { Dificuldade no treinamento dos } \\
\text { funcionários para o manuseio dos } \\
\text { programas e equipamentos }\end{array}$ & & & & & \\
\hline Falta de Linhas de Financiamento & & & & & \\
\hline
\end{tabular}

( ) Evento/Capacitação/Palestras

( ) Internet

( ) TV/Radio

( ) Empresa de Consultoria em AP

( ) Instituição de Pesquisa e/ou Ensino.

( ) Revendedores de máquinas e equipamentos para $\mathrm{AP}$

( ) Extensão Rural

( ) Outros viticultores adotantes de VP

( ) Outros:

23. Na sua opinião, qual é o maior benefício da VP? Marque as três opções que considera os maiores benefícios do uso da Viticultura de Precisão.

( ) Redução nos custos de produção

( ) Tomada de decisão rápida e certa

( ) Melhorar a qualidade da uva

( ) Aumentar a produtividade das videiras

( ) Reduzir o uso de defensivos agrícolas e melhorar o meio ambiente

( ) Uso racional de insumos e melhorar o meio ambiente

( ) Detectar o ponto ótimo de colheita para melhorar a qualidade do vinho produzido

( ) Facilitar o manejo das videiras

( ) Melhoria na qualidade do solo

( ) Não se verifica nenhum benefício

( ) Outros:

24. Dentre as técnicas/ferramentas de Viticultura de Precisão abaixo, você pretende utilizar quais em sua propriedade? Marque até cinco opções correspondentes as técnicas/ferramentas que considera de maior utilidade. Caso alguma técnica/ferramenta não esteja especificada nas opções, descreva-a no item Outros.

( ) Georreferenciamento
( ) Mapa de produtividade

( ) Mapa de qualidade

( ) Análise georreferenciada do Solo

( ) Análise georreferenciada de tecido vegetal

( ) Condutividade elétrica do solo

( ) sensoriamento remoto

( ) Robôs agrícolas

( ) Aplicação de fertilizantes a taxa variada

( ) Aplicação de defensivos a taxa variada

( ) colheita segmentada

( ) Monitoramento georreferenciado de parâmetros de qualidade da uva

( ) Imagens de VANT's - "drones"

( ) Outra:

( ) Não pretendo utilizar

( ) Rede de sensores sem fio

\section{Barreiras para o uso da viticultura de precisão}

Marque o Nível de Concordância que melhor corresponde a sua opinião quanto aos problemas apresentados a seguir.

25. Na sua opinião, quais são as barreiras para a utilização da Viticultura de precisão na sua região? Marque com X no Nível de Concordância que melhor corresponde a sua opinião quanto aos problemas apresentados.

26. Você faz uso de alguma técnica/ferramenta de Viticultura de Precisão em sua propriedade?
( ) Sim
( ) Não

\section{Você e o uso da viticultura de precisão}

Nesta secção as questões pretendem conhecer as técnica/ferramentas de viticultura de precisão que você utiliza em sua propriedade.

27. Há quanto tempo iniciou com a Viticultura de precisão em sua propriedade?

28. Quais técnicas/ferramentas de Viticultura de Precisão são utilizadas na propriedade? Marque quantas opções forem necessárias. Caso alguma técnica/ferramenta não esteja especificada nas opções, descreva-a no item Outros.

( ) Georreferenciamento

( ) Mapa de produtividade

( ) Mapa de qualidade

( ) Análise georreferenciada do Solo

( ) Análise georreferenciada de tecido vegetal

( ) Condutividade elétrica do solo

( ) sensoriamento remoto

( ) Robôs agrícolas

( ) Aplicação de fertilizantes a taxa variada

( ) Aplicação de defensivos a taxa variada

( ) colheita segmentada

( ) Monitoramento georreferenciado de parâmetros de qualidade da uva

( ) Imagens de VANT's - "drones"

( ) Outra:

( ) Não pretendo utilizar

( ) Rede de sensores sem fio

29. Qual a Área cultivada com Viticultura de Precisão?

30. Em que variedades utiliza a Viticultura de Precisão? Uvas viníferas (eutopeias) - Vitis vinífera : Ex.:Cabernet Sauvignon, Merlot, Cabernet Franc, Tannat, Pinot Noir, Syrah, Alicante Bouschet, Tempranillo, Moscato Branco, 


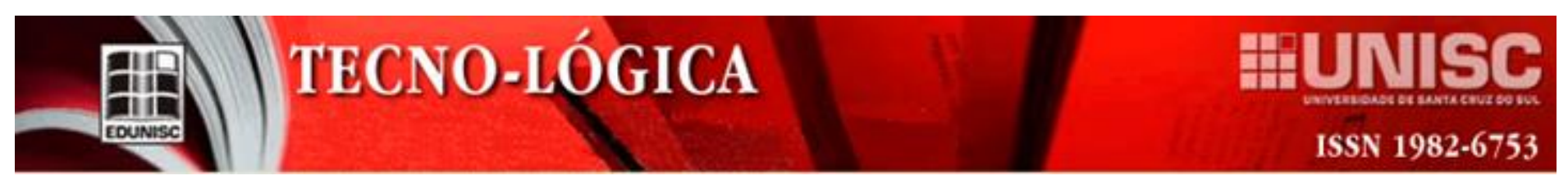

\begin{tabular}{|c|c|c|c|c|c|}
\hline \multirow[b]{2}{*}{ Problemas } & \multicolumn{5}{|c|}{$\begin{array}{c}\text { Nível de } \\
\text { Concordância }\end{array}$} \\
\hline & $\begin{array}{l}\text { o } \\
0 \\
0 \\
.0 \\
-7 \\
-0\end{array}$ & 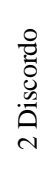 & 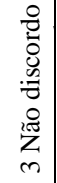 & 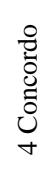 & 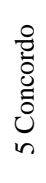 \\
\hline Alto custo das tecnologias de VP & & & & & \\
\hline Falta de linhas de financiamento & & & & & \\
\hline Falta de pessoas qualificadas & & & & & \\
\hline Falta de informação sobre as tecnologias de VP & & & & & \\
\hline Falta de prestadores de serviço em VP & & & & & \\
\hline Custo elevado dos prestadores de serviço & & & & & \\
\hline Dificuldade de operacionalizar as tecnologias & & & & & \\
\hline $\begin{array}{l}\text { Falta de recursos para implantar o sistema } \\
\text { completo de VP }\end{array}$ & & & & & \\
\hline Nem sempre a VP gera lucro & & & & & \\
\hline $\begin{array}{l}\text { Dificuldade no treinamento dos funcionários para } \\
\text { o manuseio dos programas e equipamentos }\end{array}$ & & & & & \\
\hline
\end{tabular}

34. Quanto às dificuldades do uso da viticultura de precisão, assinale com $X$ no nível de concordância que mais se aproxima da sua opinião quanto aos problemas apresentados abaixo:

A Universidade Federal de Santa Maria e os pesquisadores agradecem a sua colaboração com a presente pesquisa!

Obrigado!

Riesling Itálico, Chardonnay, Prosecco.. entre outras. Uvas americanas/híbridas - Ex.: Isabel, Bordô, Concord, Jacquez, Herbemont, Cynthiana, Niágara Branca, Niágara Rosada, Couderc 13, Moscato Embrapa, BRS Lorena, Seyval... entre outras

( ) Uvas viníferas (europeias)

( ) Uvas americanas e híbridas

( ) Outros:

31. O uso da viticultura de precisão tem reduzido o seu custo de produção de uvas? Assinale a alternativa que mais se aproxima dos resultados médios de sua propriedade.

( ) Não, os custos mantiveram-se os mesmos

( ) Não, os custos aumentaram

( ) Sim, em menos de $10 \%$

( ) Sim, de 11 a $20 \%$

( ) $\mathrm{Sim}, \mathrm{de} 21$ a $30 \%$

( ) Sim, mais que $31 \%$

( ) Sim, mas não sei especificar o quanto.

32. Com a utilização da viticultura de precisão você tem notado aumento na produtividade das uvas ao longo dos anos de uso dessa tecnologia? Assinale a alternativa que mais se aproxima dos resultados médios de sua propriedade.

( ) Não houve aumento na produtividade

( ) aumento inferior a 5\%

( ) aumento entre 6 e $10 \%$

( ) aumento entre 11 e $15 \%$

( ) aumento entre 16 e $20 \%$

( ) aumento acima de $20 \%$

( ) Sim, mas não sei especificar o quanto.

( ) Não, a produtividade diminuiu

33. Com a utilização da viticultura de precisão você tem notado aumento na qualidade das uvas ao longo dos anos de uso dessa tecnologia? ( ) Não. ( ) Sim.

Dificuldades do uso da viticultura de precisão

Marque o Nível de Concordância que melhor corresponde a sua opinião quanto aos problemas apresentados a seguir. 